DOI:

УДК 004.4’2, 004.93

О.Г. Байбуз, д.т.н., професор, obaybuz@ua.fm

Л.М. Божуха, к. ф.-м. н., доцент, bozhukha.li@gmail.com

О.Д. Федій, aleksandra.fedii@gmail.com

Дніпровський національний університет імені Олеся Гончара, м. Дніпро

\title{
АВТОМАТИЗАЦІЯ ПРОЦЕСУ ОТРИМАННЯ ВІДСТАНІ ВІД МОБІЛЬНОГО ПРИСТРОЮ ДО ОБ'ЄКТА
}

Розпізнавання об'єктів і вимірювання відстані до них є необхідними опиіями в багатьох областях. Розпізнавання образів на зображеннях є дуже великим спектром завдань, який починається з простих символів $i$ закінчується виділенням конкретних масок на зображенні, що характеризують певні класи. У роботі пропонується модифікований алгоритм визначення відстані від мобільного пристрою до об'єкта при використанні методу паралакса та інструментарію згорткових нейронних мереж. Проведено експеримент і надані результати порівняння 3 іншими існуючими методами визначення відстані.

Ключові слова: пошук відстані; паралакс; далекоміри; виділення об'єктів; розпізнавання образів.

Recognizing objects and measuring distances to them is a necessary option in many areas. Image recognition in images is a very large range of tasks, which begins with simple characters and ends with the allocation of specific masks in the image that characterize certain classes. The paper proposes a modified algorithm for determining the distance from a mobile device to an object using a parallax method and a tool for convolutional neural networks. An experiment was conducted and the results of comparison with the other existing methods of distance determination were provided.

Key words: distance search; parallax; range finder; object selection; pattern recognition.

\section{Постановка проблеми}

Останні розробки програмного забезпечення надають можливість використовувати гаджети не тільки як засіб для комунікацій, а й для вирішення завдань прикладного характеру.

Представляють інтерес завдання виявлення, розпізнавання та ідентифікації об'єкта, який рухається і знаходиться на далекій відстані.

В останні роки розпізнавання образів знаходить все більше застосування в повсякденному житті. Розпізнавання мови і рукописного тексту значно спрощує взаємодію людини 3 комп'ютером, розпізнавання друкованого тексту використовується для перекладу документів в електронну форму.

Дослідження і розробка методів і алгоритмів автоматичного аналізу і розуміння зображень продиктовані активним розвитком інформаційних технологій, що використовуються в системах штучного інтелекту [6]. Розвиток таких технологій стимулюється зростаючою швидкодією обчислювальної техніки, здатної швидко і з високою точністю обробляти великі обсяги даних.

Один із провідних напрямків в області аналізу і розуміння зображень складає розпізнавання образів, яке тісно пов'язане з проблематикою технічного зору. Дослідження і розробка методів і алгоритмів автоматичного аналізу і розуміння зображень продиктовані активним розвитком інформаційних технологій, що використовуються в системах штучного інтелекту [9]. Розвиток таких технологій стимулюється зростаючим швидкодією обчислювальної техніки, здатної швидко і з високою точністю обробляти великі обсяги даних. Один із провідних напрямків в області аналізу і розуміння зображень складає розпізнавання образів, яке тісно пов'язане 3 проблематикою технічного зору [11].

Процес розпізнавання об'єкта на зображенні можна розділити на пошук об'єкта на зображенні і порівняння знайденого об'єкта з об'єктами з бази даних (штучні нейронні мережі). 
Актуальним завданням можна вважати дослідження методів вимірювання відстані до об'єкта при використанні мобільних додатків.

Аналіз останніх досліджень та публікацій

В даний час існують різні пристрої, які можуть визначати відстань до потрібного людині об'єкта. Більшість таких пристроїв засновані на лазерних, ультразвукових датчиках і датчиках, що використовують радіохвилі. Їх головним недоліком $є$ залежність результату вимірювання від кута відбивання і матеріалу, що відбиває світло [8].

Також існують програми та пристрої, в основі яких лежить принцип дослідження зображень, отриманих за допомогою відеокамер і оптичних систем. Дані методи мають ряд недоліків, один 3 них - наявність механічного переміщення істотно впливає на час отримання результату [3].

\section{Формулювання мети дослідження}

Мета дослідження полягає в розробці та дослідженні таких методів визначення параметрів об'єктів, які дозволять, в порівнянні з відомими методами, збільшити швидкість, точність і достовірність отримання цих параметрів, а також автоматизувати процес отримання відстані до об'єкта.

Для досягнення поставленої мети необхідно вирішити такі завдання:

1. Здійснити порівняльний огляд існуючих методів визначення відстані.

2. Розробити новий метод визначення характеристик об'єкта, що рухається.

3. Розробити алгоритм розпізнавання об'єкта на зображенні, який буде найбільш ефективно підходити до розробленого методу.

4. Розробити метод і алгоритм для визначення відстані до об'єкта по зображенню.

\section{Виклад основного матеріалу}

Основним елементом етапу обчислення відстані до об'єкта є фотокамера апарату. Спосіб визначення відстані за допомогою камери заснований на отриманні одного відеокадру, отриманні калібрувальних характеристик камери [7].

Щоб визначити відстань до потрібного об'єкту, система повинна розпізнати об'єкт. Під розпізнаванням розуміється віднесення об'єкта до певного класу обраної класифікації. Для розпізнавання об'єктів запропоновано використовувати нейронні мережі. Штучні нейронні мережі - математичні моделі, а також їх програмні та апаратні реалізації, побудовані за принципом організації та функціонування мереж нервових клітин живого організму [14].

Процес розпізнавання можна розділити на чотири етапи:

1. Обробка основних властивостей об'єкта, таких як форма, колір, контрастність і тощо.

2. Групування основних властивостей на основі подібності.

3. Опис візуального представлення об'єкта за допомогою логічних структур в пам'яті.

4. Зіставлення семантичних атрибутів з візуальним представленням, що забезпечує загальний зміст, i, отже, розпізнавання об'єкта [7].

Згорткові нейронні мережі обробляють вихідне зображення не в повному обсязі, а окремими «порціями», послідовно зменшуючи його розмір або виділяючи характерні найбільш важливі ознаки.

У цих мережах формуються так звані карти ознак, які сторонньому спостерігачеві здаються розмитими, спотвореними копіями вихідного зображення, але для нейронної мережі мають зовсім інший зміст, містять інваріанти і характерні ознаки. Основна ідея згорткової нейронної мережі полягає в чергуванні субдіскретізіруючих (S-layers) шарів, згортальних (C-layers) шарів, а також повнозв'язних (F-layers) вихідних шарів [12].

Вхідні дані кожного значення пікселя нормуються в діапазоні від 0 до 1 за формулою (1).

$$
f(p, \min , \max )=\frac{\rho-\min }{\max -\min },
$$

де $f$ - функція нормалізації; $p$ - значення конкретного кольору пікселя від 0 до 255 ; $\min -$ мінімальне значення пікселя - 0 ; max — максимальне значення пікселя -255 .

Розмір у всіх карт сверточного шару — однакові та розраховуються за формулою (2). 


$$
(w, h)=(m W-k W+1, m H-k H+1),
$$

де $(w, h)$ - розмір карти; $m W$ - ширина попередньої карти; $m H-$ висота попередньої карти; $k W$ - ширина ядра; $k H$ - висота ядра.

Операція згортки є результатом операції над двома функціями $f$ та $g$ :

$$
\begin{gathered}
(f * g)(x)=\int_{R^{d}} f(y) g(x-y) d y=\int_{R^{d}} f(x-y) g(y) d y ; \\
f, g: R^{d} \rightarrow R
\end{gathered}
$$

де $x, y-$ відліки функцій; $f-$ вихідна матриця зображення; $g$ - ядро згортки (фільтр), $g=0.5 *$ (значення в вузлі).

Неформально цю операцію можна описати таким чином - вікном розміру ядра $g$ проходимо з заданим кроком (зазвичай 1 ) все зображення $f$, на кожному кроці поелементно множимо вміст вікна на ядро g, результат підсумовується і записується в матрицю результату.

Чергування шарів дозволяє складати карти ознак з карт попереднього шару, що сприяє на практиці розпізнаванню складних ієрархій ознак [4]. У згортальних шарах кожен фрагмент зображення поелементно множиться на невелику матрицю ваг, результат піддається операції підсумовування.

Для обчислення значення використовується матриця, звана ядром згортки. Зазвичай ядро згортки $є$ квадратною матрицею $n * n$, де $n-$ непарне. Під час обчислення нового значення обраного пікселя ядро згортки центрується щодо нього. Навколишні пікселі також накриваються ядром. Далі вираховується сума, де складовими є твори значень пікселів на значення комірки ядра, що накрила даний піксель. Сума ділиться на суму всіх елементів ядра згортки. Вхідні дані представляють собою зображення розмірністю $N * N$ в кількості $D$. Ядро згортки визначається матрицею $k * k$. Згортка зображення проводиться з $H$ ядрами згортки для кожної області зображення.

За рахунок крайових ефектів розмір вихідних матриць зменшується:

$$
x_{j}^{l}=f\left(\sum_{i} x_{i}^{l} * k_{j}^{l}+b_{j}^{l}\right),
$$

де $x_{j}^{l}$ - карта ознак; $f()-$ функція активації; $b_{j}^{l}-$ коефіцієнт здвигу шару 1 для карти ознак $j$; $k_{j}^{l}$ — ядро згортки ј карти, шару $1 ; *$ - операція згортки входу $x$ з ядром $k$.

Згортка однієї області і одного ядра виділяє одна ознака. Таким чином, після процедури згортки виділяється $H$ ознак. Згортку починають з верхнього лівого елемента вхідного вектора, потім рухаються в праву сторону, до моменту досягнення кордону. Далі слід зміщення вниз на один елемент і рух в ліву сторону. Подібний алгоритм повторюється, поки не буде досягнута нижня права межа. Використання згорткових шарів дозволяє значно зменшити кількість параметрів, що настроюються класифікатора. Кількість ознак розраховується за такою формулою: $H=(N-k+1)^{2}$.

Шари підвибірки необхідні для зменшення розмірності ознак. Вони надають робастними ознаками щодо шумів і спотворень. На кожному шарі відбувається формування декількох таких карт.

Існує два основних способи об'єднання ознак: об'єднання за максимальним значенням і об'єднання за середнім значенням: в обох випадках вхідний простір перетвориться в двовимірний простір [1,2].

Відстань визначається на підставі метричних і кутових розмірів об'єкта [10]. Калібрувальні характеристики камери включають фокусну відстань, розмір і співвідношення сторін пікселя, положення сенсора камери щодо оптичної осі, дані про кількість елементів (пікселів) в матриці камери, огляд камери по вертикалі / горизонталі, співвідношення сторін. Додаток розраховує відстань до об'єкта за допомогою методу паралакса. 
Паралакс використовується в геодезії і астрономії для вимірювання відстані до віддалених об'єктів. На явищі паралакса заснований бінокулярний зір. Паралакс далекоміра — кут, під яким видно об'єкт під час наведення на різкість за допомогою оптичного далекоміра [13].

При розробці програмного забезпечення використовувався математичний апарат вимірювання зміни видимого положення об'єкту відносно віддаленого фону в залежності від положення спостерігача [15]. Використовуючи ідею метода паралаксу визначається відстань між точками спостереження $L$ (база) і кут зсуву $\theta$. Відстань до об'єкта обчислюється $D=L /(2 \sin \theta / 2)$, для малих кутів $(\theta-$ в радіанах $) D=L / \theta$.

Для визначення дистанції з використанням формули «тисячної» початковими умовами $\epsilon$ ширина або висота предмета (мети), до якого знаходиться відстань. Визначення за наявними оптичних приладів кутової величини цього предмета в тисячних надає можливість обчислення відстані $D=1000 \mathrm{~V} / \theta$, де $\theta$ - кут, під яким видно предмет в тисячних, $V$ - метрична (тобто в метрах) відома ширина або висота мети. Ширина (висота) $V$ задається вручну, кут нахилу $\theta$ обирається з внутрішнього датчика приладу [13].

Додаток не обробляє зображення, які є завантаженими з камери. Надається можливість зміни одиниць відстані.

Проведемо аналіз роботи програми. Розглянемо фактичні результати роботи, і швидкість виконання (табл. 1).

Таблиия 1. Результати роботи різних методів

\begin{tabular}{|l|c|c|}
\hline & Розмір об'єкту & Відстань \\
\hline За допомогою лінійки & $7 \mathrm{~cm}$ & $30 \mathrm{~cm}$ \\
\hline Smart Distance & $7 \mathrm{~cm}$ & $35 \mathrm{~cm}$ \\
\hline Розроблена програма & $7 \mathrm{~cm}$ & $32 \mathrm{~cm}$ \\
\hline
\end{tabular}

У табл. 2 представлені дані на більшу відстані.

Таблиия 2. Результати роботи різних методів

\begin{tabular}{|l|c|c|}
\hline & Розмір об'єкту & Відстань \\
\hline За допомогою лінійки & $75 \mathrm{~cm}$ & $9000 \mathrm{~cm}$ \\
\hline Smart Distance & $75 \mathrm{~cm}$ & $10000 \mathrm{~cm}$ \\
\hline Розроблена програма & $75 \mathrm{~cm}$ & $8704 \mathrm{~cm}$ \\
\hline
\end{tabular}

\section{Висновки та перспективи подальших досліджень}

Запропоновано інформаційну технологію визначення відстані до об'єкта при обробці відео потоку.

Технологія передбачає можливості обробки відео потоку, створення ідентифікатора об'єктів і настройка характеристик пристрою.

Засобами розробленого Android-додатки проведено аналіз отриманих даних. Дослідження кількісних характеристик отриманих результатів дає можливість аналізу використання комбінацій методу на основі нейронних мереж разом з методом паралакса.

У практичній частині розроблений алгоритм вимірювання відстані. В його основі лежить геометричний закон прямокутного трикутника. Також був розроблений засіб для вимірювання кутів орієнтації в просторі і вимірювання відстані.

Була досліджена похибка засобу вимірювання. Для цього були проведені експериментальні дослідження, що представляють собою порівняння результатів вимірювання зі стандартизованими засобами вимірювань. Проведено обробку отриманих даних. 


\section{Список використаної літератури}

1. Lin H.-Y. Depth from motion and defocus blur / H.-Y.Lin, C.-H. Chang // Optical Engineering. December 2006. Vol. 45 (12). No. 127201. Pp. 1-12.

2. Robinson $\mathrm{Ph}$. Gaussian blur identification using scale-space theory / Ph. Robinson, Yu. Roodt, A.Nel // Faculty of Engineering and Built Environment. University of Johannesburg, South Africa. 2007. Pp. 68-73.

3. Ron Ohlander. Picture Segmentation Using a Recursive Region Splitting Method / Ron Ohlander, Keith Price, D. Raj Reddy // Computer Graphics and Image Processing, volume 8. - 1978. - pp 313-333.

4. Wang H. Effective improvement for depth estimated based on defocus images / H.Wang, F.Cao, Sh.Fang, Cao Yang, Ch.Fang // Journal of computers. April 2013. Vol. 8. No. 4. Pp. 888-894.

5. Айвазян С. А. Прикладная статистика: классификация и снижение размерности. / С. А.Айвазян, В. М. Бухштабер, И. С. Енюков, Л. Д. Мешалкин - М.: Финансы и статистика, 1989. С. 41.

6. Алфимцев А.Н. Сравнение методологий разработки систем интеллектуального взаимодействия / А.Н. Алфимцев, Д.А. Локтев, А.А. Локтев // Вестник МГСУ 2013. № 5. 200-208.

7. Божуха Л.М. Про алгоритм аналізу зображення на основі емпіричних методів / Л.М. Божуха, О.Д. Федій // XV Міжнародна науково-практична конференція "Математичне та програмне забезпечення інтелектуальних систем" (MPZIS-2017), м. Дніпро (23-25 листопада 2017 р.). Інформаційні технології обробки даних для прийняття рішень. - 2017. - С. 28-29.

8. Гейдаров П.Ш. Алгоритм определения расположения и размеров объектов на основе анализа изображений объектов, / П.Ш. Гейдаров // Компьютерная оптика, 2011, том 35, № 2, с. 275-280.

9. Грузман И.С. Цифровая обработка изображений в информационных системах: Учебное пособие / И.С. Грузман, В.С. Киричук. - Новосибирск : НГТУ, 2002. - 352 с.

10. Козлов В.Л. Измеритель дальности и размерных параметров объектов на основе цифровой фотокамеры / В.Л. Козлов, И.Р. Кузьмичев // Вестник БГУ, 2011, Сер.1, №1, с. 33-38.

11. Позин, Н. В. Моделирование нейронных структур / Н.В. Позин. - М.: Наука, 1970. - 264 с.

12. Татузов, А. Л. Нейронные сети в задачах радиолокации / А.Л. Татузов. - М.: Радиотехника, 2009. $-432 \mathrm{c}$.

13. Федій О.Д. About the algorithm of finding the distance to the object in a video frame / О.Д. Федій, О.Г. Байбуз, Л.М. Божуха // V Конференція "Компьютерное моделирование в наукоемких технологиях", м. Харків (22-25 травня 2018 р.). - 2018. - С. 43-44

14. Хайкин, С. Нейронные сети / С. Хайкин. - М.: Издательский дом «Вильямс», 2006.

15. Яштолд-Говорко В. А. Фотосъёмка и обработка. Съемка, формулы, термины, рецепты / В. А. Яштолд-Говорко. - Изд. 4-е, сокр. - М.: «Искусство», 1977. - 343 с.

\section{AUTOMATIZATION OF THE PROCESS OF RECEIVING FROM A MOBILE DEVICE TO A OBJECT}

Baybuz O.G., Bozhukha L.M., Fedii O.D.

\footnotetext{
Abstract

Recent software developments provide the ability to use gadgets not only as a means of communication, but also for solving application-specific problems. Interesting is the task of detecting, recognizing and identifying an object that moves and is located far away. The distance to the object is one of the main characteristics that are determined in different spheres of life.

An urgent task can be considered research by measuring methods the distance to the object when using mobile applications.
} 
The purpose of the study is to substantiate, develop and study the parallax range finder. The purpose of the work is to create a software product that allows for you to calculate at what distance the camera is located from the smartphone object.

Achievement of the set goal will allow solving the following tasks:

- conducting an analytical review of methods of measuring distance and orientation angles; smartphone;

- development of the algorithm for measuring the distance and orientation angles using a

- development of means of measuring the distance and angle of orientation using a smartphone on the Android platform.

The information technology of determination of distance to an object in processing of video stream is offered.

The technology includes the ability to process video streams, create an object identifier and configure the characteristics of the device.

The means of the developed Android-application has been analyzed by the obtained data. Investigation of the quantitative characteristics of the obtained results makes it possible to analyze the use of combinations of the method based on neural networks along with the parallax method.

In the practical part, an algorithm for measuring distance is developed. It is based on the geometric law of a rectangular triangle. A tool was also developed for measuring the orientation angles in space and measuring distance.

Measurement error was investigated. To do this, experimental research was carried out, which is a comparison of measurement results with standardized means of measurement. The processing of the received data is carried out.

Research results can be used in engineering geodesy, in military affairs, in photographs for precise and rapid focusing, in tourism, in agriculture, in bombing systems, in navigation, in astronomical research, in hunting and rifle purposes, and in construction activities.

\section{References}

[1] Lin H.-Y. Depth from motion and defocus blur / H.-Y.Lin, C.-H. Chang // Optical Engineering. December 2006. Vol. 45 (12). No. 127201. Pp. 1-12.

[2] Robinson Ph. Gaussian blur identification using scale-space theory / Ph. Robinson, Yu. Roodt, A.Nel // Faculty of Engineering and Built Environment. University of Johannesburg, South Africa. 2007. Pp. 68-73.

[3] Ron Ohlander. Picture Segmentation Using a Recursive Region Splitting Method / Ron Ohlander, Keith Price, D. Raj Reddy // Computer Graphics and Image Processing, volume 8. - 1978. - pp 313-333.

[4] Wang H. Effective improvement for depth estimated based on defocus images / H.Wang, F.Cao, Sh.Fang, Cao Yang, Ch.Fang // Journal of computers. April 2013. Vol. 8. No. 4. Pp. 888-894.

[5] Ayvazyan S. A. (1989). Prikladnaya statistika: klassifikatsiya i snizheniye razmernosti [Applied Statistics: Classification and Dimension Reduction]. Moscow: Finance and Statistics [in Russian].

[6] Alfimtsev A.N., Loktev D.A. \& Loktev A.A. (2013). Sravneniye metodologiy razrabotki sistem intellektual'nogo vzaimodeystviya [Comparison of methodologies for developing systems of intellectual interaction] Vestnik MGSU [in Russian].

[7] Bozhukha L. M. \& Fedii O.D. (2017) Pro alhorytm analizu zobrazhennya na osnovi empirychnykh metodiv [On the algorithm of image analysis based on empirical methods]. Dnipro: XV International scientific and practical conference "Mathematical and software of intelligent systems" (MPZIS-2017) [in Ukrainian].

[8] Heydarov P.Sh. (2002). Algoritm opredeleniya raspolozheniya i razmerov ob"yektov na osnove analiza izobrazheniy ob"yektov [Algorithm for determining the location and size of objects based on the analysis of images of objects]. Novosibirsk: NSTU [in Russian].

[9] Gruzman I.S. \& Kirichuk V.S. (2002). Tsifrovaya obrabotka izobrazheniy v informatsionnykh sistemakh: Uchebnoye posobiye [Digital image processing in information systems: Tutorial]. Novosibirsk: NSTU [in Russian]. 
[10] Kozlov V.L. \& I.R. Kuzmichev (2011). Izmeritel' dal'nosti i razmernykh parametrov ob"yektov na osnove tsifrovoy fotokamery [Measuring instrument of range and dimensional parameters of objects on the basis of a digital camera]. Bulletin of BSU [in Russian].

[11] Pozin N.V. (1970). Modelirovaniye neyronnykh struktur [Modeling of neural structures] M .: Science [in Russian].

[12] Tatuzov A. L. (2009) Neyronnyye seti $\mathrm{v}$ zadachakh radiolokatsii [Neural networks in radiolocation problems]. M .: Radio Engineering [in Russian].

[13] Fedii O.D., Baybuz O.G. \& Bozhukha L.M. (2018). About the algorithm of finding the distance to the object in a video frame. Kharkiv: V Conference "Computer modeling in science-intensive technologies" [in Ukrainian].

[14] Khaikin S. (2006). Neyronnyye seti [Neural networks]. M .: Williams Publishing House [in Russian].

[15] Yashtold-Govorko V. A. (1977). Fotos"yomka i obrabotka. S"yemka, formuly, terminy, retsepty [Photographing and processing. Shooting, formulas, terms, recipes]. M .: "Art" [in Russian]. 